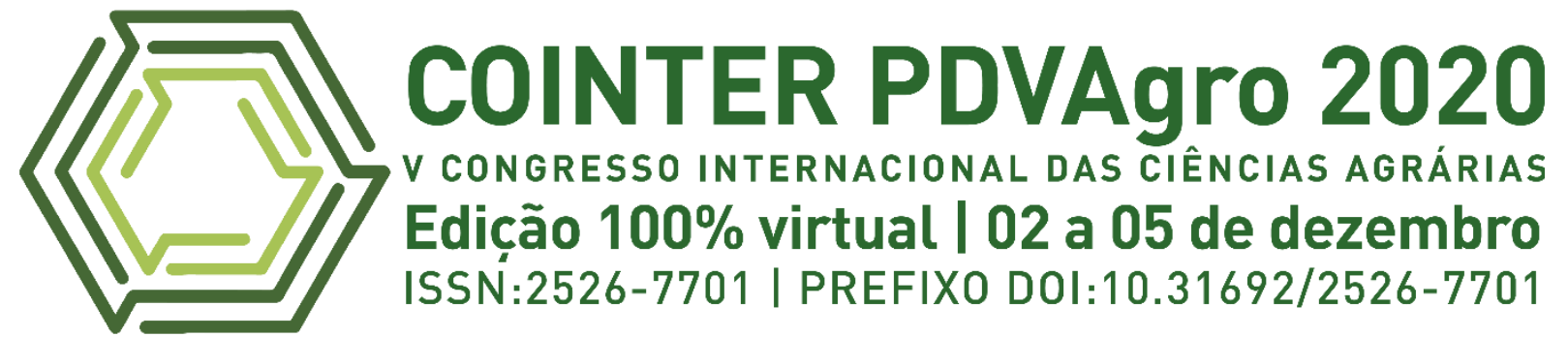

\title{
SOLUÇÕES AGRÍCOLAS E FLORESTAIS PARA UMA INDÚSTRIA TÊXTIL MAIS SUSTENTÁVEL
}

\section{SOLUCIONES AGRÍCOLAS Y FORESTALES PARA UNA INDUSTRIA TEXTIL MÁS SOSTENIBLE}

\section{AGRICULTURAL AND FORESTRY SOLUTIONS FOR A MORE SUSTAINABLE TEXTILE INDUSTRY}

\author{
Apresentação: Comunicação Oral \\ Carlos Rafael Silva de Oliveira ${ }^{1}$; Afonso Henrique da Silva Júnior ${ }^{2}$
}

DOI: https://doi.org/10.31692/2526-7701.VCOINTERPDVAgro.0392

\begin{abstract}
RESUMO
Ao longo de décadas a indústria têxtil mudou pouco em relação à execução de seus processos fabris, principalmente nos países pobres e emergentes, que invariavelmente são os maiores produtores neste nicho. Muitos dos processos de produção se mantiveram os mesmos ou muito parecidos à forma como eram executados em sua origem, exceto pelo melhoramento dos equipamentos, que atualmente são mais ergonômicos, seguros, duráveis, eficientes e automatizados. Porém, as cargas poluentes geradas e os impactos florestais e aquáticos continuam sendo um problema grave, que tornará este sistema fabril cada vez mais nocivo e insustentável. Para piorar, a moda e o marketing ao criarem tendências e necessidades no desenvolvimento acelerado das coleções, intensificam o consumismo irresponsável e agilizam o ciclo de descarte desses materiais o que gera mais lixo em intervalos de tempos cada vez menores. Por estas razões, é importante mostrar como esses problemas afetam a sociedade e como é urgente a busca por soluções mais efetivas. $\mathrm{O}$ interesse da ciência na busca por novas alternativas de cultivo de fibras e meios de fabricação dos produtos têxteis de forma mais consciente e responsável, por exemplo, por meio da exploração sustentável dos recursos florestais e até mesmo a arborização de lavouras convencionais (agrossilvicultura), já é uma realidade, embora, com um avanço um tanto quanto lento. Neste sentido, o presente trabalho buscou relatar as deficiências do sistema têxtil atual e suas desvantagens no âmbito ecológico, para a partir disso apresentar as potencialidades que a floresta tem para um desenvolvimento alternativo mais sustentável dessa indústria. $\mathrm{O}$ conteúdo apresentado tem a intenção de tratar, neste contexto, uma ideia de reengenharia, algo que possa ser repensando, reavaliado, renovado e reestruturado no âmbito dos processos têxteis tradicionais, levando em consideração o equilíbrio ambiental e a adoção da mentalidade de sociedade 5.0.

Palavras-Chave: indústria têxtil, recursos florestais, sustentabilidade, agrossilvicultura, sociedade 5.0.

\section{RESUMEN}

A lo largo de las décadas, la industria textil ha cambiado poco con relación a la ejecución de sus procesos de manufactura, principalmente en países pobres y emergentes, que invariablemente son los mayores

\footnotetext{
${ }^{1}$ Engenheiro Têxtil (Universidade Estadual de Maringá - UEM), aluno de Doutorado em Engenharia Química (Universidade Federal de Santa Catarina - UFSC), carlos.oliveira@posgrad.ufsc.br

${ }^{2}$ Engenheiro Agroindustrial-Agroquímico (Universidade Federal do Rio Grande - FURG), aluno de Mestrado em Engenharia Química (Universidade Federal de Santa Catarina - UFSC), afonso.ufsc@gmail.com
} 


\title{
SOLUÇÕES AGRÍCOLAS E FLORESTAIS PARA UMA INDÚSTRIA TÊXTIL
}

productores de este nicho. Muchos de los procesos de producción se han mantenido iguales o muy similares a la forma en que se ejecutaban en su origen, solo que con la diferencia de mejorar el equipo, que actualmente es más ergonómico, seguro, duradero, eficiente y automatizado. Sin embargo, las cargas contaminantes generadas y los impactos forestales y acuáticos siguen siendo un problema grave, lo que hará que este sistema de fabricación sea cada vez más dañino e insostenible. Para colmo, la moda y el marketing, creando tendencias y necesidades en el desarrollo acelerado de colecciones, intensifican el consumismo irresponsable y aceleran el ciclo de disposición de estos materiales, que genera más desperdicio en intervalos de tiempo cada vez más cortos. Por estas razones, es importante mostrar cómo estos problemas afectan a la sociedad y cuán urgente es la búsqueda de soluciones más efectivas. El interés de la ciencia en la búsqueda de nuevas alternativas para el cultivo de fibras y formas de fabricar productos textiles de una manera más consciente y responsable, por ejemplo, mediante la explotación sostenible de los recursos forestales e incluso la forestación de cultivos con el uso de la agroforestería, ya es una realidad, aunque con un avance bastante lento. En este sentido, el presente trabajo buscó reportar las deficiencias del sistema textil actual y sus desventajas ecológicas, con el fin de presentar el potencial que tiene el bosque para un desarrollo alternativo más sustentable de esta industria. El contenido presentado tiene la intención de tratar, en este contexto, la idea de la reingeniería como algo que se puede repensar, reevaluar, renovar y reestructurar en el ámbito de los procesos textiles tradicionales, teniendo en cuenta el equilibrio ambiental y la adopción de la mentalidad de sociedad 5.0. Palabras Clave: industria textil, recursos forestales, sostenibilidad, agroforestería, sociedad 5.0.

\begin{abstract}
Over the decades, the textile industry has changed little concerning the execution of its manufacturing processes, mainly in poor and emerging countries, which are invariably the largest producers in this niche. Many of the production processes have remained the same or very similar to the way they were originally performed, only with the difference of the equipment, which is currently more ergonomic, safe, durable, efficient, and automated. However, the polluting loads generated, and the forest and aquatic impacts remain a serious problem, which will make this manufacturing system increasingly harmful and unsustainable. To make matters worse, fashion and marketing, creating trends and needs in the accelerated development of collections, intensify irresponsible consumerism and speed up the cycle of disposal of these materials, which generates more waste in increasingly shorter time intervals. For these reasons, it is important to show how these problems affect society and how urgent the search for more effective solutions is. The interest of science in the search for new alternatives for fibers production and means of manufacturing textile products more consciously and responsibly, for example, through the sustainable exploitation of forest resources and even the use of agroforestry, is already a reality, though, with a rather slow progress. In this sense, the present work sought to report the deficiencies of the current textile system and its ecological disadvantages, to present the potential that the forest has for a more sustainable alternative development of this industry. The content presented is intended to treat, in this context, the idea of reengineering as something that can be rethought, reevaluated, renewed and restructured within the scope of traditional textile processes, considering the environmental balance, and the adoption of the society 5.0 concept.
\end{abstract}

Keywords: textile industry, forest resources, sustainability, agroforestry, society 5.0.

\section{INTRODUÇ̃̃̃O}

Atualmente, a indústria têxtil é um dos sistemas de produção mais ameaçadores do meio ambiente, os impactos negativos dessa indústria vão desde a lavoura até o produto acabado. O sistema produtivo têxtil exige um elevado consumo de água potável e energia, seja no cultivo das fibras ou nos tratamentos químicos industriais. É fato que os processos químicos de limpeza, tingimento, estamparias e acabamentos das fibras, fios e tecidos utilizam altas cargas de produtos químicos tóxicos e corantes, que consequentemente geram grandes 
quantidades de resíduos sólidos (lodo têxtil) e líquidos (efluentes). Os produtos como peças de vestuário e artigos de cama, mesa e banho nas expedições geram ainda mais lixo devido ao elevado volume de embalagens comerciais unitárias que os acompanham (na maioria das vezes não biodegradáveis). Para piorar, a moda e o marketing ao criarem tendências e necessidades no desenvolvimento acelerado das coleções, intensificam o consumismo irresponsável, e agilizam o ciclo de descarte desses materiais, o que gera mais lixo em intervalos de tempos cada vez mais curtos.

A indústria têxtil evoluiu muito pouco em relação ao melhoramento de seus processos fabris, principalmente nos países pobres e emergentes, que invariavelmente são os maiores produtores neste nicho. Muitos dos processos de produção se mantiveram os mesmos, ou muito parecidos à forma como eram executados em sua origem; exceto pelo melhoramento dos equipamentos, que atualmente são mais ergonômicos, seguros, duráveis, eficientes e automatizados. Porém, as cargas poluentes geradas e os impactos florestais e aquáticos continuam sendo um problema grave, que tornará este sistema cada vez mais nocivo e insustentável.

Não apenas o processamento industrial, mas o uso das mesmas matérias-primas, tais como fibras e corantes, tem se mantido até hoje. O algodão, por exemplo, continua sendo a fibra mais utilizada no mundo para fins têxteis e a mais consumida dentre as fibras naturais. $\mathrm{O}$ crescimento populacional e o aumento da demanda desses produtos têm agravado os impactos ambientais, seja pelo elevado descarte de resíduos químicos na natureza, pelo alto consumo de água potável em lavouras e indústrias ou pelo avanço do desmatamento para ampliação de áreas de cultivo, a fim de suprir as necessidades humanas.

Portanto, há uma necessidade iminente de que cientistas, pesquisadores e profissionais da área têxtil comecem a despertar preocupação e interesse pela reengenharia desse segmento industrial, que é um dos mais importantes da sociedade pela elevada geração de bens e serviços, mas, também, um grande causador de impactos ambientais. A ideia de reengenharia está relacionada ao desenvolvimento de novas alternativas de matérias-primas, produtos químicos, rotas de processamento, maquinários e formas de cultivo agrícola, que superem as commodities e os sistemas de produção atuais, primem pelo monitoramento e controle da geração de poluentes e pelo uso consciente de recursos naturais.

O desmatamento irresponsável e por vezes criminoso para o avanço de áreas agrícolas, leva à reflexão sobre o uso de outras fibras naturais alternativas, que não exijam um cultivo com os mesmos impactos ambientais ocasionados, por exemplo, pelo cultivo de algodão, que precisa de extensas áreas para plantio, elevado consumo de água, fertilizantes e pesticidas. $\mathrm{O}$ 


\section{SOLUÇÕES AGRÍCOLAS E FLORESTAIS PARA UMA INDÚSTRIA TÊXTIL}

mesmo problema conduz à reflexão sobre a adoção de outras formas de cultivo, como, por exemplo, o estudo, adequação e utilização da agrossilvicultura para a cultura do algodão.

Fora do campo agrícola, o campo industrial também pode se adequar ao uso de produtos como corantes, pigmentos e mordentes naturais obtidos/extraídos de vegetações florestais, adoção do uso de agentes tensoativos orgânicos e embalagens biodegradáveis. Neste contexto, também é possível pensar na minimização do uso industrial da água, por meio do desenvolvimento de tecnologias que permitam que processos químicos têxteis, por exemplo, sejam realizados com o uso de fluídos em estado supercrítico, o que possibilitaria o uso de compostos como o $\mathrm{CO}_{2}$ solvente no lugar da água para o tingimento de fibras.

Segundo o relatório Forests for Fashion ( 2019), a indústria têxtil e de vestuário atualmente contribui com US\$ 2,4 trilhões para a manufatura global; emprega 75 milhões de pessoas em todo o mundo, sendo a maior parte mulheres; é responsável por 8 a $10 \%$ das emissões mundiais de gases de efeito estufa; é responsável por cerca de $20 \%$ da poluição de águas residuais em todo o mundo; e tem US\$ 500 bilhões de perda todos os anos devido a subutilização de roupas e à falta de reciclagem.

De fato, é preciso uma reengenharia têxtil, que leve em consideração o uso inteligente da ciência e da tecnologia; que possibilite a superação das formas de produção atuais ainda tão primárias e ineficientes sob o ponto de vista ecológico, visando o aproveitamento máximo e consciente dos recursos florestais, para assim possibilitar o surgimento de uma nova indústria, sustentável e adequada ao futuro que todos desejamos. Portanto, o presente trabalho tem por objetivo resgatar a importância de se pensar nessa linha de estudos e apresentar uma visão geral à respeito dos pontos negativos dos processos têxteis atuais, que representam um campo amplo de oportunidades de melhoria; e como os recursos florestais podem contribuir para um equilíbrio entre produtividade e preservação dos ecossistemas.

\section{FUNDAMENTAÇÃO TEÓRICA}

Os materiais têxteis são estruturas cuja construção e composição é feita de fibras finas e flexíveis de origem natural (obtidas diretamente de fontes vegetais ou animais), artificial (obtidas a partir da regeneração de polímeros naturais por um processo industrial), e/ou sintética (obtidas a partir de subprodutos da indústria do petróleo). Esses materiais são usados diretamente na confecção de vestuários (roupas, calçados e acessórios), artigos de cama, mesa e banho, tapetes, revestimento de móveis (sofá, colchão, travesseiro, banco de automóveis, etc.), cortinas, artigos de decoração; artesanato; técnicos; inteligentes e/ou funcionais (DE 
OLIVEIRA et al., 2017), entre outros. O fato desses materiais estarem presentes em praticamente todos os tipos de ambiente, revela o quanto esse nicho industrial é importante, principalmente por ser considerado um dos ramos principais de manufatura nos países em desenvolvimento (BUSCIO et al., 2019).

A cadeia produtiva têxtil se inicia na lavoura, pois o cultivo de fibras naturais para fins têxteis constitui uma parte do sistema produtivo. $\mathrm{O}$ algodão, por exemplo, é considerado a fibra natural mais importante, o seu cultivo e consumo para fins têxteis corresponde à mais de $82 \%$ do total de cultivo e consumo de fibras naturais do planeta. $\mathrm{O}$ algodão representa $33 \%$ de todas as fibras produzidas e consumidas no mundo (BAYDAR; CILIZ; MAMMADOV, 2015; GÜNTHER et al., 2017) e é constituído essencialmente de celulose ( 94\%) (MENACHEM, L., PEARCE, 2006; SUN et al., 2005; YANG et al., 2020). Entretanto, o sistema produtivo de algodão demanda extensas áreas de plantio, o que é agravado pelo aumento da demanda desses produtos em razão do crescimento populacional. Segundo o relatório The state of the world's forests de 2020, publicado pela Organização de Alimentos e Agricultura das Nações Unidas (FAO), a busca pela ocupação de solo para plantio agrícola tem aumentado o desmatamento de florestas no mundo todo (FAO AND UNEP, 2020).

Atualmente as florestas cobrem $31 \%$ das terras do planeta, metade dessa porção está intacta na forma de floresta primária, e mais de $50 \%$ de todas as florestas do mundo estão em cinco países: Brasil, Rússia, China, EUA e Canadá. O Brasil concentra cerca de $12 \%$ de toda área florestal do planeta, ficando atrás apenas da Rússia com $20 \%$. No entanto, o desmatamento e a degradação florestal vêm crescendo em níveis alarmantes. Desde 1990, cerca de 420 milhões de hectares $\left(4,2\right.$ milhões de $\left.\mathrm{km}^{2}\right)$ de floresta e toda sua biodiversidade foram dizimados, isso equivale à uma área maior do que a Índia (3,3 milhões de $\mathrm{km}^{2}$ ) (FAO AND UNEP, 2020). Entre 2015 e 2020, a taxa de desmatamento foi de cerca de 10 milhões de hectares por ano, em sua maioria ocasionada por queimadas e invasões ilegais. Segundo a FAO 2020 a expansão agrícola continua sendo o principal motivo do desaparecimento das florestas, principalmente para o cultivo de soja e óleo de palma, embora dentre as principais ameaças de superexploração a curto prazo, está a conversão das terras para a produção de algodão.

No mundo, o Brasil é o quinto maior produtor de algodão em pluma, ficando atrás apenas da China, Índia, EUA e Paquistão (ESTEVE-TURRILLAS; DE LA GUARDIA, 2017). Neste contexto, não é difícil entender o aumento do desmatamento, queimadas e extermínio indígena no Brasil nos últimos anos. Segundo o Relatório Anual de Desmatamento do Brasil de 2019, publicado pelo MapBiomas e INPE (Instituto Nacional de Pesquisas Espaciais), cerca de 1,2 milhões de hectares de vegetação nativa foram desmatadas em todos os biomas do país, 


\section{SOLUÇÕES AGRÍCOLAS E FLORESTAIS PARA UMA INDÚSTRIA TÊXTIL}

com isso o Brasil (e o mundo) perderam uma área florestal equivalente a 8 vezes a área da cidade de São Paulo/SP (AZEVEDO et al., 2019). Segundo o relatório, cerca de $60 \%$ da área desmatada está na Amazônia e 34 \% no Cerrado, seguido pelo Pantanal (1,4\%), Caatinga (1 \%), Mata Atlântica (0,88 \%) e Pampa (0,05 \%); sendo os estados mais atingidos o Amazonas, Mato Grosso, Bahia, Pará e Rondônia; ironicamente, os maiores estados produtores de algodão do Brasil.

Para o ano de 2020 as estatísticas não estão concluídas, mas é notável a piora na gestão do meio ambiente em relação à 2019; as manchetes no mundo todo têm reportado a devastação das florestas brasileiras e o descaso do atual Governo Federal e do Ministério do Meio Ambiente (AZEVEDO et al., 2019). Incontestavelmente, os brasileiros têm assistido suas riquezas naturais queimarem sob a gestão de seus atuais governantes irresponsáveis; que incentivam a exploração; a grilagem (exploração e apropriação ilegal das terras nacionais); agridem a pesquisa acadêmica séria de controle ambiental; e estão descaradamente a serviço de seus interesses próprios, e não da nação. Embora o desmatamento seja o fator mais grave impulsionado pela cultura do algodão, outros problemas do crescimento dessa cultura são a demanda de recursos hídricos potáveis para irrigação e o elevado uso de pesticidas que chega a $11 \%$ do consumo mundial (ESTEVE-TURRILLAS; DE LA GUARDIA, 2017).

Outro problema ambiental grave causado pelo consumo inconsequente é a geração de lixo não biodegradável como, por exemplo, produtos plásticos. Ao se pensar em plásticos logo vem à cabeça garrafas PET, embalagens alimentícias, copos descartáveis, canudos, entre outros objetos, mas quase ninguém pensa em têxteis. Poucas pessoas têm o interesse em olhar a etiqueta ao comprar a peça e saber sua composição. Mas se esse exercício fosse realizado, seria possível com facilidade observar o grande volume de roupas contendo poliéster, poliamida, (poli)acrílico, poliuretano, polietileno, entre outras fibras que são puramente plástico; os mesmo usados para fazer, por exemplo, as embalagens e as garrafas PET. Muitas dessas fibras aparecem na etiquetas por seus nomes comerciais, como Lycra ${ }^{\circledR}$ e Creora ${ }^{\circledR}$ que são poliuretano/elastano; Nylon ${ }^{\circledR}$, Caprolan ${ }^{\circledR}$ e Perlon ${ }^{\circledR}$ que são poliamidas; Kevlar ${ }^{\circledR}$ e Nomex $\AA$ que são poliaramidas; Trevira ${ }^{\circledR}$, Diolen ${ }^{\circledR}$ e Terylene ${ }^{\circledR}$ que são poliésteres, Acrilan ${ }^{\circledR}$ e Orlon $\AA$ que são (poli)acrílicos, e assim por diante. O fato é que a velocidade de consumo e descarte desses materiais tem gerado acúmulo de plásticos no solo, nas águas doce e nos oceanos, causando a contaminação de ecossistemas, a morte de animais e o desiquilíbrio em muitos biomas. Estudos estimam que entre 4 a 12 milhões de toneladas de plástico por ano vão parar em mares e oceanos, e preveem um aumento duplo no acúmulo de plásticos na natureza (incluindo micro e nano plásticos) até 2030 (PATRÍCIO SILVA et al., 2021). 
Ao final de 2019 o mundo foi surpreendido pelo surgimento do Covid-19, um vírus que obrigou o planeta a entrar em quarentena a fim de minimizar as mortes por infecção. Este problema tem prevalecido até o momento e o mundo imergiu nos últimos meses em crises políticas, econômicas e sociais, agravadas pelo vírus. Patrício Silva et al. (2021) realizaram um estudo sobre como o Covid-19 agravou a poluição pelo o aumento do consumo de plásticos, desde as embalagens de produtos de entrega delivery (que cresceram muito na pandemia) até o uso de máscaras descartáveis. As máscaras descartáveis, assim como os absorventes íntimos, lenços umedecidos, flanelas de limpeza doméstica e fraldas descartáveis são feitas de TNT, que é um produto têxtil feito a partir de fibras plásticas. Os autores citam, por exemplo, que o volume de lixo de uso médico em hospitais aumentou 10 vezes durante a pandemia, eles observaram em alguns casos um aumento de 350 a $370 \%$ do lixo plástico, atribuído na maior parte ao descarte de peças de TNT, como máscaras, toucas, aventais, pantufas e luvas.

Do âmbito industrial, os processos têxteis também geram grandes impactos ambientais, em especial os setores tecnicamente chamados de Beneficiamento Têxtil (primário, secundário e terciário), onde ocorrem tratamentos físico-químicos de preparação (engomagem/desengomagem, mercerização, etc.), limpeza (purga, lavagem e alvejamento), coloração (tingimento, branqueamento, etc.), arte (estamparias) e acabamento (amaciamento, funcionalização, etc.) das fibras, fios e tecidos (ARAUJO, M.; CASTRO, 1986; COOK, 2001; MENACHEM, L., PEARCE, 2006; NEEDLES, 1986). Nestes setores altas cargas de produtos químicos são utilizados para tratar o material bruto e torná-lo adequado ao uso final. Toneladas de produtos como ácidos, álcalis, agentes oxidantes/redutores, emulgadores, detergentes industriais, amaciantes, resinas poliméricas, complexantes metálicos, pigmentos, entre outros, são exaustivamente usadas nas indústrias têxteis do mundo todo, diariamente. Mas em especial, o elevado consumo de água potável, alta carga de corantes e sais usados nas tinturarias são merecedores de destaque quanto aos impactos ambientais (BUSCIO et al., 2019). Existe uma estimativa que cerca de 10 mil tipos diferentes de corantes e pigmentos têxteis sintéticos estão comercialmente disponíveis no mundo e a produção global chega a 800 mil toneladas de corante têxtil por ano (AYADI; SOUISSI, 2015).

Atualmente para cada $1 \mathrm{~kg}$ de produto têxtil acabado são necessários cerca de $200 \mathrm{a}$ $400 \mathrm{~L}$ de água para o seu processamento completo. Considerando que de 2018 para 2019 o Brasil (quarto maior produtor têxtil do mundo) sozinho produziu 1,2 milhões de toneladas de material têxtil; com isso é possível ter uma noção do volume absurdo de consumo de água e geração de efluentes desses processos (ABIT, 2018). Cerca de $95 \%$ das águas residuais da indústria têxtil provêm do processo de tingimento, enquanto, $5 \%$ do volume gerado 


\section{SOLUÇÕES AGRÍCOLAS E FLORESTAIS PARA UMA INDÚSTRIA TÊXTIL}

corresponde às águas de enxágue (ELSAHIDA et al., 2019). O conteúdo de metal como cromo, chumbo e zinco é encontrado em efluentes têxteis, esses metais são cumulativos em organismos animais e podem gerar doenças como, por exemplo, o câncer (ELSAHIDA et al., 2019).

Atualmente os efluentes têxteis são tratados por via biológica e/ou físico-química, porém, os processos biológicos embora sejam bastante eficientes na remoção de matéria orgânica dissolvida, são pouco eficientes na descoloração da água devido à resistência dos corantes aos ataques microbiológicos (BUSCIO et al., 2019; ROBINSON et al., 2001). Portanto, para a descoloração a indústria recorre ao processo físico-químico, normalmente do tipo coagulação-floculação, os quais empregam sais metálicos que atuam como coagulantes e ao final geram um lodo/lama tóxica (contendo compostos aromáticos e metais pesados), que normalmente é secada e aterrada.

Erroneamente, alguns estudiosos defendem que o importante no tratamento de efluentes têxteis é remover os demais produtos químicos e ajustar o $\mathrm{pH}$ da água, pois na concepção desses pesquisadores, os corantes como estrutura orgânica são biodegradáveis e seu impacto na natureza não vai além do desconforto visual da mudança da cor dos corpos d'água

que recebem o efluente. É preciso reafirmar que quando os corantes têxteis não são devidamente removidos da água, esses compostos podem sim, causar sérios danos aos ecossistemas aquáticos. A mudança da coloração dos corpos d'água alteram o atravessamento natural da luz na água, dessa forma a vegetação aquática ao deixar de receber luz começa a ter um processo de fotossíntese prejudicado. Portanto, torna-se deficiente o fornecimento de oxigênio dissolvido na água, que por sua vez é fundamental para a respiração de peixes e outros animais aquáticos. Mas o problema dos corantes sintéticos industriais vai além, eles possuem uma biodegradação lenta, e muitos deles, principalmente as classes usadas para o tingimento de algodão, são nocivos à saúde humana por serem altamente carcinogênicos.

Os peixes de água doce contaminados com corantes sintéticos podem fazer parte do consumo alimentar de seres humanos, que indiretamente ingerem essas substâncias por meio do consumo desses alimentos. Nos últimos anos, algumas pesquisas relacionadas à toxicidade dos corantes têxteis sintéticos, apresentaram resultados que comprovaram os seus efeitos prejudiciais à saúde humana (AYADI; SOUISSI, 2015). Em especial, os corantes do tipo Azo, podem ocasionar efeitos colaterais metabólicos, efeitos mutagênicos e carcinogênicos em animais e humanos. Os danos à saúde e ao DNA se deve à ação direta do corante e/ou seus metabólitos intermediários, como o naftaleno, benzidina, e outras aminas aromáticas liberadas no organismo (AYADI; SOUISSI, 2015). 


\section{METODOLOGIA}

Este estudo foi desenvolvido em duas fases. A primeira, consistiu em uma busca/revisão sistemática da literatura, combinando termos como "agrossilvicultura", "fibras vegetais", "recursos florestais", "impactos ambientais", "indústria têxtil" e "moda sustentável", na plataforma do ScienceDirect e Google Acadêmico. Em seguida, os artigos foram selecionados considerando o objetivo do estudo e a relevância do conteúdo. A segunda, consistiu na busca de dados em relatórios e documentos de análise oficiais do governo, diferentes organizações e instituições, como a FAO (Organização de Alimentos e Agricultura das Nações Unidas); o INPE (Instituto Nacional de Pesquisas Espaciais); o MapBiomas Brasil; e a ABIT (Associação Brasileira da Indústria Têxtil e de Confecção), para mapear dados dos impactos ecológicos nacionais e globais e exemplos de métodos de cultivo mais sustentáveis, visando a produção de fibras naturais para a indústria têxtil.

\section{RESULTADOS E DISCUSSÃO}

Considerando as questões anteriores com relação aos impactos ambientais causados pela indústria têxtil, uma pesquisa voltada à apresentação de possíveis soluções agrícolas e florestais para a minimização desses problemas é discutida neste tópico.

Neste contexto, a agrossilvicultura (Figura 1) é uma modalidade agrícola, que engloba as múltiplas formas de interação entre árvores e culturas de plantio para o estabelecimento de um sistema agroecológico. É baseado na convivência intima de dois sistemas diferentes (agroalimentar e florestal) em equilíbrio, onde ambos contribuem mutuamente para a mitigação das mudanças climáticas geradas pelos desmatamentos; a preservação dos ecossistemas; a redução do uso de pesticidas e fertilizantes industriais na lavoura; a melhora da qualidade física, química e biológica do solo; e a prevenção da desertificação (DA SILVA JÚNIOR et al., 2020a; DE OLIVEIRA et al., 2020; MUCHANE et al., 2020; ZHANG, W. et al., 2019).

Para que uma determinada cultura consiga germinar e se desenvolver até a colheita, o fator mais importante é a fertilidade/qualidade do solo. A qualidade do solo está diretamente relacionada à alguns parâmetros como o Carbono Orgânico do Solo (COS), a umidade, a disponibilidade de nutrientes como nitrogênio $(\mathrm{N})$ e fósforo $(\mathrm{P})$ e ao $\mathrm{pH}$ do solo. O COS é um indicador da saúde do solo, porque está associado à disponibilidade de nutrientes para a planta e para os microrganismos responsáveis pelo seu desenvolvimento, à capacidade de retenção hídrica e à fertilidade do solo (MUCHANE et al., 2020). A presença de $\mathrm{N}$ e $\mathrm{P}$ totais no solo são indicadores de fertilidade, porque são elementos essenciais que plantas e microrganismos 


\section{SOLUÇÕES AGRÍCOLAS E FLORESTAIS PARA UMA INDÚSTRIA TÊXTIL}

utilizam para se desenvolver, por isso a deficiência desses elementos no solo é um limitador de produção. $\mathrm{O}$ pH do solo é importante porque influencia diretamente na disponibilidade de nutrientes, na toxicidade do solo e na atividade microbiana ecossistêmica.

Todos esses parâmetros foram estudados por Muchane et al. ( 2020), os autores relataram em seus estudos que as taxas de erosão do solo são reduzidas em até 50 \% em sistemas agroflorestais, quando comparados às monoculturas de lavouras. Os autores também relataram um aumento de $21 \%$ de COS em comparação às terras onde são desenvolvidas monoculturas; um aumento de 13 e $46 \%$ no armazenamento e disponibilidade de nitrogênio, respectivamente, em sistemas agroflorestais; um aumento de $11 \%$ na disponibilidade de $\mathrm{P}$ em comparação à monocultura de lavouras; e um ligeiro aumento do $\mathrm{pH}$ do solo em $2 \%$ em sistemas agroflorestais. Dessa maneira, os autores concluíram que a agrossilvicultura contribui significativamente, de forma positiva, tanto para o agronegócio quanto para a preservação do meio ambiente.

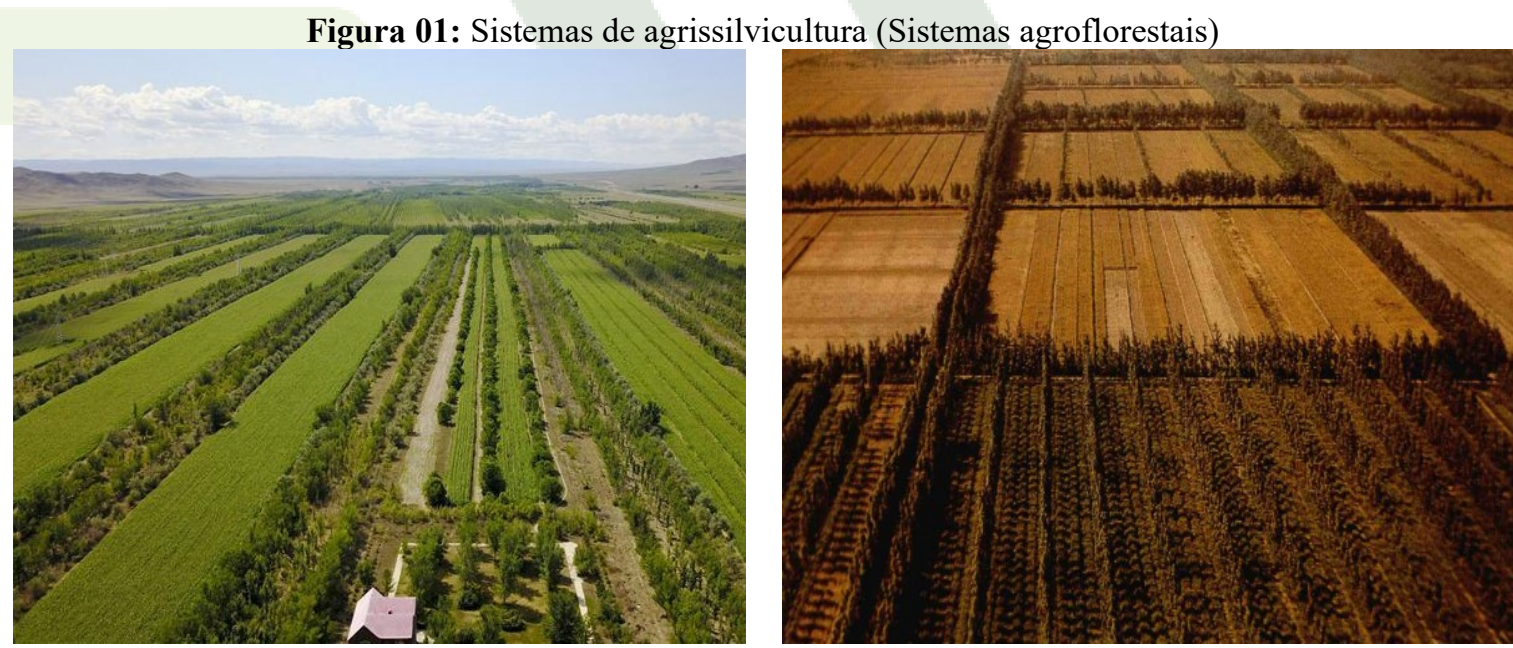

Fonte: Agroforestry Systems in China ( 1991).

A agrossilvicultura é praticada na China há milhares de anos. As plantações em alamedas é uma modalidade bastante usada no país e normalmente envolve o cultivo de plantas perenes lenhosas, geralmente para a produção de frutas ou castanhas; neste sistema, enquanto as árvores forma fileiras, as lavouras (trigo, milho, soja, amendoim, algodão, etc.) são cultivadas entre as fileiras de árvores (ZHANG, W. et al., 2019). Xinjiang é uma província semiárida da China onde há escassez de chuvas, porém, há abundância de luz e alguns oásis que servem como fontes de irrigação. Nesta região, o governo local recentemente buscou maneiras de mitigar a erosão eólica que ocorre durante o inverno nas plantações de trigo e algodão. Com sucesso, a plantação de árvores frutíferas em meio as lavouras tem revertido o processo de 
desertificação, tem gerado renda e desenvolvido a indústria de frutas na região. O sistema agroflorestal de Xinjiang começou em 2008 e atualmente já possui uma área de 1,2 milhões de hectares (ZHANG, D. et al., 2014; ZHANG, W. et al., 2019).

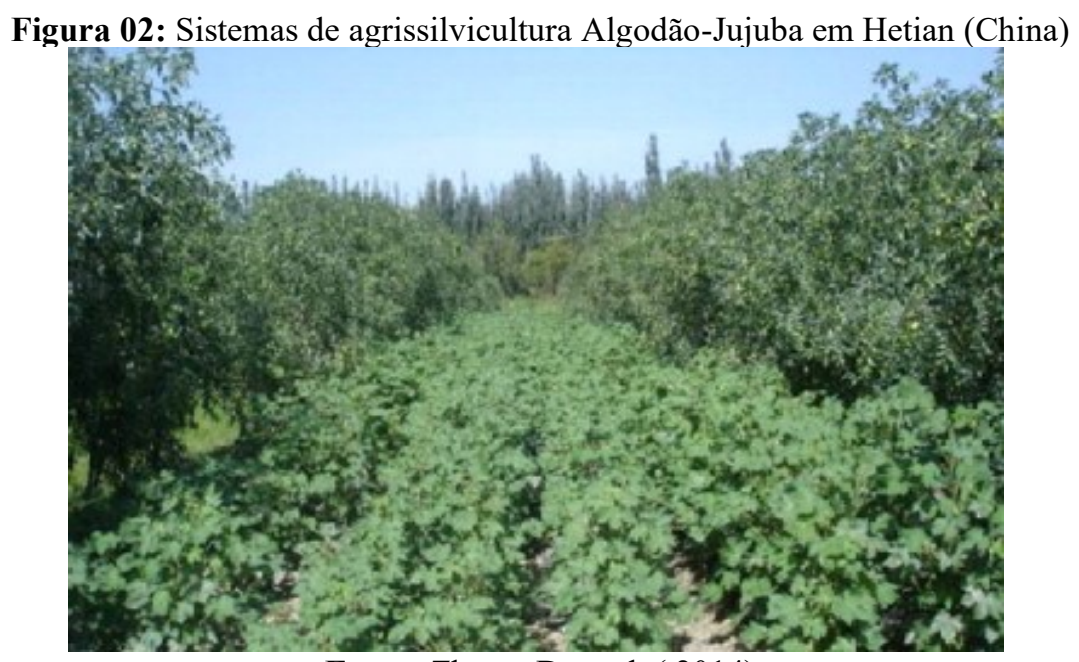

Fonte: Zhang, D. et al. ( 2014)

No antigo oásis Hetian na região de Uygur ao sul de Xinjiang, dentre os sistemas agroflorestais da região, a combinação de algodão e jujuba (Zizyphus jujuba) é bastante comum e em 2011 já ocupava 32 mil hectares de plantação (Figura 2). Este sistema é considerado pelos produtores locais um sistema bastante lucrativo, de alto rendimento e de alta eficiência no uso dos recursos, especialmente durante a fase jovem das jujubas (primeiros 10 anos) (ZHANG, D. et al., 2014).

Algumas pesquisas pelo mundo vêm buscando uma melhor compreensão da viabilidade da silvicultura para o cultivo de algodão. Um sistema de cultivo de algodão e sorgo (Sorghum moench) em uma silvicultura de carité (Vitellaria paradoxa Gaertn) em Benin (África) foi estudado por Gnanglè et al. (2013). Os autores mostraram que os parâmetros de produtividade para o algodão e o sorgo, isto é, altura das plantas, rendimento e biomassa fresca, são dependentes da distância entre a cultura e as árvores, e também do sombreamento. Wanvestraut et al. ( 2004), estudaram a competição por água em um sistema de algodão e noz-pecã (Carya illinoensis) em solo franco-arenoso em Jay na Flórida (EUA). Os pesquisadores testaram o uso de barreiras de 1,2 metros de profundidade com placas de polietileno, a fim de evitar a disputa radicular de água entre as culturas (algodão e noz-pecã) e comparar o rendimento de produção com o plantio sem barreira. A equipe descobriu que a disputa por água entre as espécies ocorre entre 3 e 4 semanas após a emergência do algodão e piora entre 7 e 8 semanas seguintes, eles notaram que o sistema com barreira apresentou rendimento similar ao rendimento obtido em 


\section{SOLUÇÕES AGRÍCOLAS E FLORESTAIS PARA UMA INDÚSTRIA TÊXTIL}

uma monocultura $(677 \mathrm{~kg} / \mathrm{ha})$, enquanto que sem barreira o rendimento é bem menor (502 $\mathrm{kg} / \mathrm{ha}$ ). O experimento também revelou que a poda anual ou semestral das raízes arbóreas pode ser vantajosa para as espécies associadas, pois gera o alívio do stress hídrico entre elas.

No Brasil e em outros países pelo mundo, pouco ou nada se sabe sobre sistemas de agricultura de commodities como os adotados pela província de Xinjiang, pelo contrário, o uso dos sistemas tradicionais de agricultura só aumentam, e com eles o aumento do desmatamento, do consumo de água e do uso de pesticidas (DA SILVA JÚNIOR et al., 2020a; DE OLIVEIRA et al., 2020). Por isso, é importante que profissionais, estudantes e pesquisadores das áreas ambientais, agronômicas, têxtil e moda tenham o conhecimento dessas informações e se tornem precursores de uma nova mentalidade local.

Neste contexto, uma outra solução ambiental para mitigar os impactos negativos da cultura de algodão tradicional, é a adoção e o desenvolvimento do cultivo de outras fibras vegetais como alternativa de matéria-prima têxtil, por exemplo, fibras de linho, juta, rami, sisal, bambu, cânhamo, coco, banana, cana-de-açúcar, milkweed (Asclepias syriaca), kenaf (Hibiscus cannabinus), palmeira (Astrocaryum chambira Burret), tamareira (phoenix dactylifera), abacá (Musa textilis), paina (Ceiba speciosa), produção de algodão orgânico, ou mesmo a reciclagem dessas fibras a partir de produtos descartados (ESTEVE-TURRILLAS; DE LA GUARDIA, 2017; GHORI et al., 2018; OLIVEIRA DUARTE et al., 2019). Porém, existe um certo conformismo e acomodação das comunidades globais aos processos e produtos tradicionais. $\mathrm{O}$ fato é que existem outras fontes de matérias-primas que podem ser exploradas, adequadas, desenvolvidas e inseridas nos costumes de uma sociedade.

Há 6 mil anos, por exemplo, o linho já era comumente usado no Egito; o cânhamo e o rami são cultivados e usados para fins têxteis na China há milhares de anos; civilizações précolombianas já usavam o sisal misturados às fibras animais como lã e vicunha para confecção de roupas, no entanto, atualmente pouco ou nenhum conhecimento popular dessas fibras é observado entre consumidores na atualidade (OLIVEIRA DUARTE et al., 2019). Todas essas fibras são possíveis recursos florestais alternativos mal explorados, o que explica até hoje os meios ainda rudimentares de produção e de processamento de alguns desses materiais, como o rami, o sisal, a juta e até mesmo o linho.

Uma preocupação sobre produção sustentável já é uma realidade no campo da moda, que tem crescido e ganhado força nos últimos anos. Os pesquisadores têm entendido que a moda tem um papel fundamental na mudança do perfil dos usuários. Enquanto a engenharia atua na mudança concreta de processos e equipamentos, a moda age nas pessoas e no seu comportamento de consumo. Por isso em 2014 o governo da Suíça e outros parceiros, uniram 
forças com a UNECE (Comissão Econômica da Nações Unidas para a Europa) e a FAO na construção de um evento voltado à comemoração do dia internacional da floresta. Com o tema "Innovative Forest Fibers", o evento foi um sucesso e em 2018 a exposição "Forests for Fashion" voltou a ganhar o palco no High-Level Political Forum que aconteceu em Nova York (EUA). Em 2019 na quarta assembleia ambiental da ONU (Organização das Nações Unidas) em Nairóbi (Quênia) a iniciativa "Forests for Fashion" foi exibida na Sustainable Innovations Expo. A ONU está empenhada em transformar o caminho da moda, e em conjunto com organizações aliadas criaram o programa "United Nations Alliance for Sustainable Fashion", que visa contribuir para os objetivos de desenvolvimento sustentável por meio de ações coordenadas no setor de moda e têxtil. Na busca por se integrarem à causa, estilistas/designers, coordenadores de marca, gerentes de produto, modelistas, auxiliares de estilo e demais profissionais de moda em geral, têm buscado inspiração para novas coleções nos recursos florestais nativos e no uso minimalista de processos químicos. Isto inclui a procura e uso de novos tipos de fibras naturais, fios de diferentes composições fibrosas, corantes e pigmentos naturais até o uso de embalagens biodegradáveis, entre outros.

Um povoado tribal chamado Baganda que vive ao sul de Uganda (África Oriental) desenvolveram há centenas de anos uma técnica de obtenção de um tecido não fibroso a partir da casca de uma árvore denominada por eles de mutuba (Ficus natalensis). O tecido em tom de terracota (Figura 3) é até hoje utilizado por reis e chefes naquela cultura, e também em cerimônias de coroação e religiosas ou ainda fúnebres. A nobreza da técnica e a beleza material do produto levou este a ser reconhecido como "Patrimônio Cultural Imaterial da Humanidade" pela UNESCO (Organização das Nações Unidas para a Educação, Ciência e Cultura) a fim de proteger o conhecimento da arte, a tradição e os meios de subsistência associados à sua produção.

Venkatraman et al. (2020), estudaram a adequação prática do tecido de casca de mutuba para uso final em vestuário, e conduziram testes de caimento, vestibilidade, rigidez, maleabilidade, resistência ao rasgo, resistência à impressão de laser, estamparia de sublimação, lavagem, além de estudos da morfologia de superfície e FTIR (Espectroscopia no Infravermelho por Transformada de Fourier). Os autores concluíram que o material além de sustentável se mostrou ideal para o desenvolvimento de moda artesanal de luxo; tratamentos como tingimento, estamparia e gravações à laser são possíveis o que permite um aprimoramento do visual estético do produto; a resistência do tecido pode ser melhorada ao ser fundida com diferentes interfaces como TNT (Tecido Não-Tecido) ou entretelas; pode vir a ser um oficio com potencial lucrativo e desenvolvimento regional por meio da geração de empregos e renda. O exemplo anterior é 


\section{SOLUÇÕES AGRÍCOLAS E FLORESTAIS PARA UMA INDÚSTRIA TÊXTIL}

uma excelente representação do potencial que equipes qualificadas e engajadas da indústria da moda são capazes de realizar, em prol do bem social e ambiental.

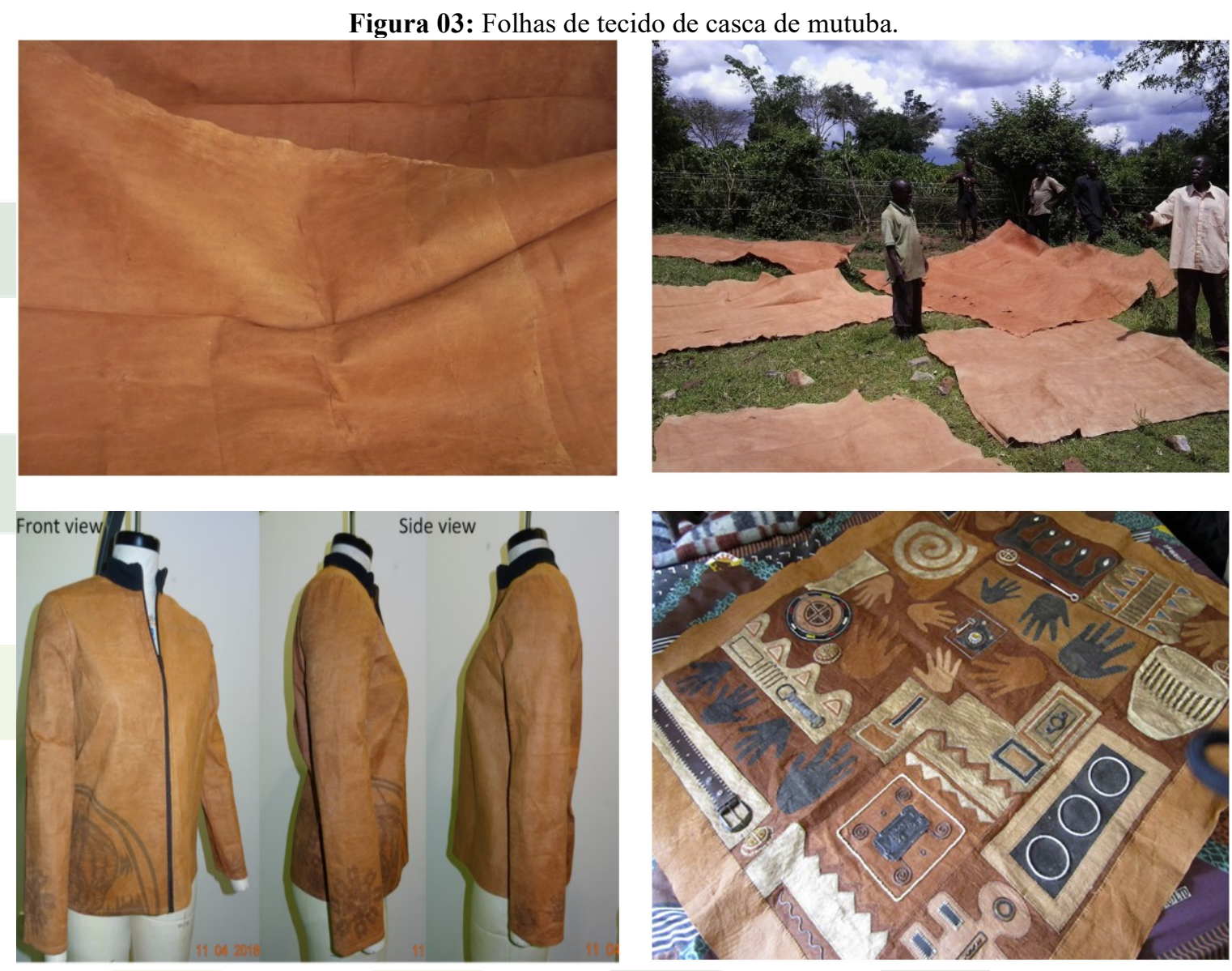

Fonte: Venkatraman; Scott; Liauw ( 2020).

Como apresentado anteriormente, um dos maiores impactos ambientais causados pela indústria têxtil é o elevado volume de efluentes contaminados, especialmente aqueles contendo altas cargas de corantes e sais. No caso de alguns corantes sintéticos, o uso de sal é fundamental para que o tingimento ocorra, pois o sal provoca a adsorção do corante nas fibras e auxilia na sua fixação e solidez (resistência da cor); e para isso são usadas grandes quantidades de sal. Os corantes naturais não apresentam o mesmo problema, a maioria deles para uma melhor fixação requerem o uso de produtos chamados “mordentes”, que geralmente, também são substâncias naturais como, por exemplo, o tanino.

A oferta disponível de corantes naturais para a indústria, em geral, ainda é de $1 \%$ da demanda mundial (10 mil toneladas), portanto, o potencial de desenvolvimento de corantes naturais é muito amplo. Os negócios no campo comercial de corantes naturais estão em plena expansão e crescimento, exceto para os corantes naturais de uso têxtil. Isso ocorre porque o 
rendimento das cores obtido com corantes naturais é muito inferior aos obtidos com corantes sintéticos, além disso, suas quantidades necessárias para o tingimento de uma mesma massa de tecido é muito maior (ELSAHIDA et al., 2019). Os corantes naturais são mais sensíveis à degradação pela luz e podem desbotar com facilidade se os cuidados de uso não forem respeitados, bem como a perda gradativa da cor pode ocorrer ao longo das lavagens caseiras. Mesmo com todas essas desvantagens os corantes naturais são sem dúvida um objeto de estudo importante e promissor, eles representam a preservação dos ecossistemas aquáticos e muito da objeção ao seu uso está mais relacionado à preocupação estética do produto do que sua aplicabilidade industrial. Isso significa dizer, que a adoção desses materiais na indústria depende muito mais da conscientização e aceitação dos consumidores, do que de sua aplicabilidade prática nos processos (ELSAHIDA et al., 2019; KUMAR; TRIPATHI, 2011).

Os corantes naturais são biodegradáveis, e podem ser classificados com base em sua estrutura química, origem e método de aplicação. Os corantes baseados em estrutura química são do tipo indigóides (azul), carotenóides (tons de amarelo, laranja e vermelho), quinonóides (tons de amarelo e vermelho), flavonóides (tons de amarelo escuro, laranja e azul), e os baseados em piridina (amarelo), betalaínas (betaxantina: amarelo e betacianina: roxo), taninos (tons de amarelo, marrom, cinza e preto quando usado como mordente com outras fontes corantes) e diidropirano (cores brasileiras CI 75280 e CI 75290). Com base em sua origem os corantes naturais podem ser de plantas (flores, frutos, sementes, folhas, madeira, pele, raízes, etc.), animais (insetos que produzem tons de vermelho e roxo) e minerais (sais metálicos, óxidos metálicos e ocre vermelho). Quanto ao processo de aplicação podem ser classificados como corantes de mordentes, corantes de cuba (índigo, roxo de Tyrian, etc.), corantes diretos (açafrão, urucum, romã e cártamo para algodão), corantes ácidos (aqueles usados para tingimento de fibras de poliamida, lã e seda), corantes básicos e dispersos (para poliéster e acetato).

Os corantes naturais podem ser obtidos pela extração florestal, pela agricultura, reciclagem de resíduos/subprodutos agrícolas, silvicultura, a partir de resíduos da indústria de alimentos e bebidas (ex.: antocianinas de borra de vinho). Os corantes naturais não servem apenas para conferir cor aos produtos têxteis, alguns possuem funções adicionais, como atividade antimicrobiana, proteção UV, atividade anti-inflamatória, repelente de insetos, entre outros (ELSAHIDA et al., 2019; KUMAR; TRIPATHI, 2011).

Os recursos florestais que podem contribuir para uma indústria têxtil mais sustentável vão além dos corantes naturais, de novas modalidades de cultivo/agricultura e novas alternativas de fibras vegetais; podem inclusive, fornecer insumos para a produção de nanoestruturas obtidas por síntese verde que servem como suporte de compostos pesticidas e 


\section{SOLUÇÕES AGRÍCOLAS E FLORESTAIS PARA UMA INDÚSTRIA TÊXTIL}

fertilizantes. Nanopesticidas e nanofertilizantes são capazes de otimizar a entrega e distribuição dos compostos ativos de forma controlada nas plantas e nas lavouras, o que aumenta a eficácia do controle de pragas e reduz a carga desses produtos aplicados, como mostra os trabalhos de Da Silva Júnior et al. ( 2020a) e De Oliveira et al. ( 2020). Vários suportes nanométricos podem ser usados para o carregamento e entrega controlada de agroquímicos na lavoura, mas um em especial, obtido a partir de biomassa (frutas, folhas, caules, etc.) por síntese verde são os carbon dots (DA SILVA JÚNIOR et al., 2020b). Os carbon dots são estruturas orgânicas com cerca de $10 \mathrm{~nm}$ e também podem ser obtidos a partir de biomassa, que são altamente disponíveis nas florestas, nos resíduos agroindustriais, inclusive em resíduos de fiação de algodão.

Outro recurso florestal altamente disponível, de manejo eficaz e exploração sustentável é a biomassa lignocelulósica. Esses materiais possuem um grande potencial para a produção de bioplásticos, em substituição as fibras sintéticas convencionais que são baseadas em produtos petroquímicos. Os bioplásticos são materiais com propriedades que se assemelham aos plásticos tradicionais, porém obtidos a partir de biomassa e não de fósseis.

Hoje em dia, os bioplásticos são obtidos a partir de produtos e resíduos da agroindústria, principalmente do milho (ácido polilático - PLA), cana-de-açúcar (bio-polietileno - BioPE), gorduras e óleos residuais (BioPE de $2^{\mathrm{a}}$ geração) (BRODIN et al., 2017). No entanto, mesmo sendo originados de recursos orgânicos renováveis, os bioplásticos não são necessariamente biodegradáveis, como é o caso do BioPE, já que o que determina a biodegradabilidade de um material não é sua origem e sim a sua estrutura química.

Os bioplásticos também podem ser derivados de recursos agroflorestais não alimentares, por exemplo, lignocelulósicos, que neste caso podem originar polímeros com um certo grau de biodegradabilidade (BRODIN et al., 2017). Sandra e Alessandro ( 2021) conduziram uma pesquisa com 696 consumidores italianos sobre a sua disposição em pagarem por três produtos bio-têxteis feitos a partir de madeira certificada (meias, camisetas e camisas). Os autores concluíram que existe um enorme interesse daquela comunidade no consumo de bioplásticos e bio-têxteis e que este mercado é promissor na economia da União Europeia. A pesquisa revelou que $95 \%$ dos consumidores estão dispostos a pagar um preço premium entre 64 a $128 \%$ por bio-têxteis feitos de fibra bioplástica obtida da madeira.

São incontáveis as soluções que podem ser aplicadas à indústria têxtil, cabem apenas à comunidade acadêmica, às empresas do ramo e os governos locais, unirem forças na busca da consolidação de práticas sustentáveis de produção, com investimento em pesquisa e desenvolvimentos tecnológicos. 


\section{CONCLUSÕES}

O estudo apresentou uma visão geral dos impactos negativos da indústria têxtil na atualidade e como novas práticas agrícolas, recursos florestais e agroindustriais podem propor soluções inteligentes para a construção de uma indústria têxtil mais sustentável. Ficou claro a importância da indústria da moda na adoção de políticas mais ecológicas para a construção das coleções e sua participação na mudança de comportamento do consumidor no sentido da preservação ambiental. A importância da preservação das florestas e como o meio ambiente tem sido depredado também foi um ponto forte da discussão apresentada. O trabalho buscou fornecer dados e números que ajudam o leitor a dimensionar a importância do tema e trouxe luz a real necessidade e carência de estudos que viabilizem uma evolução da indústria têxtil e moda em uma direção mais "verde".

\section{REFERÊNCIAS}

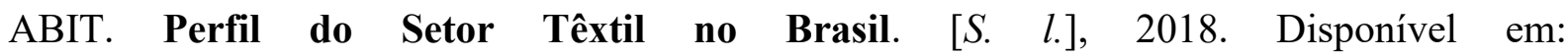
https://www.abit.org.br/cont/perfil-do-setor. Acesso em: 10 out. 2020.

ARAUJO, M.; CASTRO, E. M. Manual de Engenharia Têxtil. 1. ed. Lisboa: Ed. Fundação Calouste Gulbenkian, 1986.

AYADI, Insaf; SOUISSI, Yasmine. Chemical Synonyms, Molecular Structure and Toxicological Risk Assessment of Synthetic Textile Dyes: A Critical Review. Journal of Developing Drugs, [s. l.], v. 05, n. 01, 2015. Disponível em: https://doi.org/10.4172/23296631.1000151

AZEVEDO, Tasso Rezende de et al. Relatório Anual do Desmatamento no Brasil. São Paulo: [s. n.], 2019. E-book.

BAYDAR, G.; CILIZ, N.; MAMMADOV, A. Life cycle assessment of cotton textile products in Turkey. Resources, Conservation and Recycling, [s. l.], v. 104, p. 213-223, 2015. Disponível em: https://doi.org/10.1016/j.resconrec.2015.08.007

BRODIN, Malin et al. Lignocellulosics as sustainable resources for production of bioplastics A review. Journal of Cleaner Production, [s. l.], v. 162, p. 646-664, 2017. Disponível em: https://doi.org/10.1016/j.jclepro.2017.05.209

BUSCIO, V. et al. Reducing the environmental impact of textile industry by reusing residual salts and water: ECUVal system. Chemical Engineering Journal, [s. l.], v. 373, n. April, p. 161-170, 2019. Disponível em: https://doi.org/10.1016/j.cej.2019.04.146

COOK, J. G. Handbook of Textile Fibres Vol.I - Nature Fibres. 8th ed., ved. Cambridge: Woodhead Publishing Limited, 2001.

DA SILVA JÚNIOR, Afonso Henrique et al. Nanofertilizers: an overview. In: , 2020a, Recife/PE - Brazil. International Agribusiness Congress (CIAGRO- 2020) - Science, 
Technology and Innovation: From the field to the meal. Recife/PE - Brazil: Instituto IDV, 2020. p. 14. Disponível em: https://doi.org/doi.org/10.31692/ICIAGRO.2020.0041

DA SILVA JÚNIOR, Afonso Henrique et al. Novel carbon dots for zinc sensing from Campomanesia phaea. Materials Letters, [s. l.], p. 128813, 2020b. Disponível em: https://doi.org/10.1016/j.matlet.2020.128813

DE OLIVEIRA, Carlos Rafael Silva et al. Development of flexible sensors using knit fabrics with conductive polyaniline coating and graphite electrodes. Journal of Applied Polymer Science, [s. l.], v. 134, n. 18, p. 1-10, 2017. Disponível em: https://doi.org/10.1002/app.44785

DE OLIVEIRA, Carlos Rafael Silva et al. Nano-delivery systems of pesticides active agents for agriculture applications - an overview. In: , 2020, Recife/PE - Brazil. International Agribusiness Congress (CIAGRO- 2020) - Science, Technology and Innovation: From the field to the meal. Recife/PE - Brazil: Instituto IDV, 2020. p. 1-20. Disponível em: https://doi.org/https://doi.org/10.31692/ICIAGRO.2020.0051

ELSAHIDA, K. et al. Sustainability of the use of natural dyes in the textile industry. In: , 2019. IOP Conference Series: Earth and Environmental Science. [S. l.: s. n.], 2019. p. 012065. Disponível em: https://doi.org/10.1088/1755-1315/399/1/012065

ESTEVE-TURRILLAS, F.A.; DE LA GUARDIA, M. Environmental impact of Recover cotton in textile industry. Resources, Conservation and Recycling, [s. l.], v. 116, p. 107-115, 2017. Disponível em: https://doi.org/10.1016/j.resconrec.2016.09.034

FAO AND UNEP, 2020. The State of the World's Forests 2020 - Forests, Biodiversity and People. 1. ed. Rome: FAO and UNEP, 2020. Disponível em: https://doi.org/10.4060/ca8642en

GHORI, W. et al. A review on date palm ( phoenix dactylifera ) fibers and its polymer composites. IOP Conference Series: Materials Science and Engineering, [s. l.], v. 368, n. 1, p. 012009, 2018. Disponível em: https://doi.org/10.1088/1757-899X/368/1/012009

GNANGLÈ, Césaire Paul et al. Productivity of cotton and sorghum in an agroforestry system of shea trees (Vitellaria paradoxa gaertn) in northern Benin. Natural Science, [s. l.], v. 05, n. 02, p. 207-213, 2013. Disponível em: https://doi.org/10.4236/ns.2013.52031

GÜNTHER, Jasmin et al. Carbon and phosphorus footprint of the cotton production in Xinjiang, China, in comparison to an alternative fibre ( Apocynum ) from Central Asia. Journal of Cleaner Production, $[s . \quad$ l. $]$, v. 148, p. 490-497, 2017. Disponível em: https://doi.org/10.1016/j.jclepro.2017.01.153

KUMAR, Rakesh; TRIPATHI, Y.C. Natural Dyes from Forest Biomass. In: TRAINING MANUAL ON EXTRACTION TECHNOLOGY OF NATURAL DYES \& AROMA THERAPY AND CULTIVATION VALUE ADDITION OF MEDICINAL PLANTS. 1 sted. Dehradun: Forest Research Institute, 2011. p. 51-69. Disponível em: https://doi.org/10.13140/2.1.4934.9927

MENACHEM, L., PEARCE, E. M. Handbook of fiber chemistry. 3nd ed.ed. New York: Taylor \& Francis, 2006.

MUCHANE, Mary N. et al. Agroforestry boosts soil health in the humid and sub-humid tropics: A meta-analysis. Agriculture, Ecosystems \& Environment, [s. l.], v. 295, n. February, p. 
106899, 2020. Disponível em: https://doi.org/10.1016/j.agee.2020.106899

NEEDLES, H. L. Textile Fibers, Dyes, Finishes, and Processes - A concise guide. New Jersey: Noyes Publications, 1986.

OLIVEIRA DUARTE, Larissa et al. Textile natural fibers production regarding the agroforestry approach. SN Applied Sciences, [s. l.], v. 1, n. 8, p. 914, 2019. Disponível em: https://doi.org/10.1007/s42452-019-0937-y

PATRÍCIO SILVA, Ana L. et al. Increased plastic pollution due to COVID-19 pandemic: Challenges and recommendations. Chemical Engineering Journal, [s. l.], v. 405, n. July 2020, p. 126683, 2021. Disponível em: https://doi.org/10.1016/j.cej.2020.126683

ROBINSON, Tim et al. Remediation of dyes in textile effluent: a critical review on current treatment technologies with a proposed alternative. Bioresource Technology, [s. l.], v. 77, n. 3, p. 247-255, 2001. Disponível em: https://doi.org/10.1016/S0960-8524(00)00080-8

SANDRA, Notaro; ALESSANDRO, Paletto. Consumers' preferences, attitudes and willingness to pay for bio-textile in wood fibers. Journal of Retailing and Consumer Services, $[s$. l. $]$, v. 58, n. September 2020, p. 102304, 2021. Disponível em: https://doi.org/10.1016/j.jretconser.2020.102304

SUN, Yan et al. Brassinosteroid regulates fiber development on cultured cotton ovules. Plant and Cell Physiology, $[s$. l. $]$, v. 46, n. 8, p. 1384-1391, 2005. Disponível em: https://doi.org/10.1093/pcp/pci150

\section{UNECE/FAO. Forests for Fashion - For Sustainable Development GoalsUN ALLIANCE}

For Sustainable Fashion. Geneva: $\left[\begin{array}{ll}s . & n .\end{array}\right]$ 2019. Disponível em: http://www.unece.org/fileadmin/DAM/timber/Communications/Forests_for_Fashion_Booklet 2019.pdf.

VENKATRAMAN, Prabhuraj D.; SCOTT, Kirsten; LIAUW, Christopher. Environmentally friendly and sustainable bark cloth for garment applications: Evaluation of fabric properties and apparel development. Sustainable Materials and Technologies, [s. l.], v. 23, p. e00136, 2020. Disponível em: https://doi.org/10.1016/j.susmat.2019.e00136

WANVESTRAUT, Robert H. et al. Competition for water in a pecan (Carya illinoensis K. Koch) - cotton (Gossypium hirsutum L.) alley cropping system in the southern United States. Agroforestry Systems, $[s$. l. $]$, v. 60, n. 2, p. 167-179, 2004. Disponível em: https://doi.org/10.1023/B:AGFO.0000013292.29487.7a

YANG, Zuoren et al. Gossypium Genomics: Trends, Scope, and Utilization for Cotton Improvement. Trends in Plant Science, [s. l.], v. 25, n. 5, p. 488-500, 2020. Disponível em: https://doi.org/10.1016/j.tplants.2019.12.011

ZHA, Zhuohua et al. (org.). Agroforestry Systems in China. 7. ed. Singapura: IDRC Canada, 1991.

ZHANG, Dongsheng et al. Plant density affects light interception and yield in cotton grown as companion crop in young jujube plantations. Field Crops Research, [s. l.], v. 169, p. 132-139, 2014. Disponível em: https://doi.org/10.1016/j.fcr.2014.09.001 
ZHANG, W. et al. Competitive interaction in jujube tree/cotton agroforestry system in Xinjiang province, northwestern China. Agroforestry Systems, [s. l.], v. 93, n. 2, p. 591-605, 2019. Disponível em: https://doi.org/10.1007/s10457-017-0153-y 